\title{
Influence of bone defect position and span in 3-point bending tests: experimental and finite element analysis
}

\author{
Luis Gustavo Gonzalez OSUNA(a) \\ Carlos José SOARES(b) (iD \\ Andomar Bruno Fernandes VILELA ${ }^{(b)}$ \\ Milena Suemi IRIE(a) \\ Antheunis VERSLUIS(c) \\ Priscilla Barbosa Ferreira SOARES ${ }^{(a)}$ \\ (a) Universidade Federal de Uberlândia - \\ UFU, Department of Periodontology and \\ Implantology, Uberlândia, MG, Brazil. \\ (b) Universidade Federal de Uberlândia - UFU, \\ Department of Operative Dentistry and \\ Dental Materials, Uberlândia, MG, Brazil. \\ (c) University of Tennessee Health Science \\ Center, College of Dentistry, Department of \\ Bioscience Research, Memphis, TN, USA.
}

Declaration of Interests: The authors certify that they have no commercial or associative interest that represents a conflict of interest in connection with the manuscript.

Corresponding Author:

Priscilla Barbosa Ferreira Soares

E-mail: pbfsoares@ufu.br

https://doi.org/10.1590/1807-3107bor-2021.vol35.0001

Submitted: April 28, 2020

Accepted for publication: July 15, 2020

Last revision: July 22, 2020
Abstract: Three-point bending test is the most common mechanical test used for quantifying the biomechanical quality of bone tissue and bone healing in small animals. However, there is a lack of standardization for evaluation of bone repair by cortical perforation. The aim of this study was to determine the influence of bone defect position in the proximal metaphysis of rat tibias during load application and different span configuration on the three-point bending test outcomes. Cortical defects with $1.6 \mathrm{~mm}$ diameter were created at a standardized location on the medial surface of 60 tibias of male Wistar rats. The animals were euthanized 7 days after surgery. Five specimens were used to create 3D models for finite element analysis using high-resolution micro-CT images. Two spans ( 6 and $10 \mathrm{~mm}$ ) and three positions of the bone defect in relation to the load application (upward, frontal and downward) were evaluated experimentally $(n=10)$ and in finite element analysis $(n=5)$. Maximum load $(\mathrm{N})$ and stiffness $(\mathrm{N} / \mathrm{mm})$ were statistically analyzed with 2-way ANOVA and Tukey test $(\alpha=0.05)$. The results demonstrated that span and orientation of the bone defect significantly influenced the fracture pattern, stress distribution and force versus displacement relation. Therefore, reliable outcome can be achieved creating the bone defect at $8 \mathrm{~mm}$ from the extremity of the proximal epiphysis; placing a $10 \mathrm{~mm}$ distance span and downward facing defect position to allow a better distribution of stress and more fracture patterns that reached the bone defect target area with less intra-group variability.

Keywords: Bone and Bones; Biomechanical Phenomena; Finite Element Analysis.

\section{Introduction}

Development of new therapeutic strategies and biomaterials to improve bone repair processes or to recover bone quality under systemic or local conditions requires standardized methodological approaches. ${ }^{1,2}$ An important factor to consider in these studies is the type of defect, which may be by perforation of the cortical bone, partial osteotomy or total fracture. Each experimental model represent different mechanisms, where bone repair of cortical perforation defects occurs by intramembranous ossification, and bone repair of fracture is the result of abundant cartilaginous callus formation followed by endochondral ossification. ${ }^{3}$ Various experimental 
studies focused on the diaphysis of long bones, ${ }^{1,2,4}$ however to evaluate biomechanical effect of bone alterations, the metaphysis of a femur or tibia should be considered, since the diaphysis of long bones consist only of cortical bone and bone marrow and major changes due to bone degenerative diseases are also observed in the trabecular bone that is located in the metaphysis. $3,5,6,7,8,9$

In order to determine the effect of any therapy during the repair process of bone defects, it is essential to evaluate the structural fracture resistance. Several structural parameters such as geometry, mineral content and density are used to indirectly evaluate the biomechanical properties of bone, nonetheless, bone ability to resist fracture can only be assessed by biomechanical strength tests..$^{10}$ Different biomechanical methods can be used to characterize the structural properties of bone, among them are tensile, compression, torsion and three- or four-point bending tests. ${ }^{11}$ Three-point bending tests are the most commonly used mechanical tests to characterize bone material and biomechanical properties of long bones. ${ }^{12,13}$ Standardization of three-point bending tests on the methaphysis of long bones without bone defects has been reported, ${ }^{3,7,14}$ however, there there are no guidelines for parameters such as span and bone defect positioning. ${ }^{12,13,14}$ Adequate stability of the bone between the supports during the test must is determined by the length of metaphysis region, which constitutes a limitation for the span distance. A standardized protocol is needed to allow comparisons of data from different sources and to ensure that biomechanical properties are obtained at the targed area of the bone defect. $3,7,14$

Three-point bending tests provide structural information about the whole bone, such as stiffness and strength. However, they cannot provide local information, such as stress distribution. ${ }^{11}$ Since local stresses will ultimately determine the fracture resistance of the bone section tested, finite element analysis is essential. Finite element analysis can identify stress concentration locations, allowing a more comprehensive evaluation of subtle changes in bone fracture resistance and behavior of inner bone structures during biophysical stimuli. ${ }^{15,16}$ To the authors' knowledge, the effect of the bone defect locations and span in three-point bending tests used in metaphysis studies has not previously been assessed. The aim of this study was to determine the influence of bone defect position in the proximal metaphysis of rat tibias during load application and different span configuration on the threepoint bending test outcomes. The null hypothesis tested was that the bone effect position during the loading (upward, frontal and downward) and the different span configurations ( 6 and $10 \mathrm{~mm}$ ) does not influence the maximum load $(\mathrm{N})$, stiffness $(\mathrm{N} / \mathrm{mm})$ and stress distributions (MPa) of bone tissues using the tree-point bending test.

\section{Methodology}

\section{Characterization of the sample}

This study was carried out in strict compliance with the ethical principles for the care and use of laboratory animals and according to the ARRIVE guidelines. The protocol was approved by the Committee on the Ethics of Animal Experiments of the Federal University of Uberlândia (Protocol Number: 076/17, CEUA-UFU). Thirty male Wistar rats, clinically healthy at 8 weeks of age (300-320 g) were included. The animals were kept at the Animal Experimentation Center of the Federal University of Uberlândia in closed plastic cages with a temperature of $22^{\circ} \mathrm{C}$ and a light-dark cycle of 12 hours. Diet consisted of standard laboratory pellets (Labina, Purina, Paulínia, Brazil) and water ad libitum.

\section{Surgical procedure of bone defect creation}

The animals were submitted to anesthesia intraperitoneally, using $0.07 \mathrm{ml} / 100 \mathrm{~g}$ of muscle relaxant xylazine hydrochloride $2 \%$, and $0.1 \mathrm{ml} /$ $100 \mathrm{~g}$ of anesthetic and analgesic $10 \%$ ketamine hydrochloride. After trichotomy (Figure 1A), antissepsia was performed with $2 \%$ chlorhexidine solution and the operative area was delimited. Surgical access to the tibia methaphysis was obtained by means of a continuous longitudinal standardized incision of $2 \mathrm{~cm}$ in length. After that, the musculature was divulsed until the periosteum, which was exposed and incised. The tibia was delimited in three portions (upper, middle and lower), aiming to standardize 
the area to be manipulated, thus half of the medial face of the proximal metaphysis region was the chosen area to the creation of the bone defect. A bone defect was performed with a drill measuring $1.6 \mathrm{~mm}$ diameter (Neodent, Curitiba, Brazil) at 15,000 rpm, under irrigation with sterile saline solution of $0.9 \%$ sodium chloride (Figure 1B). The depth reference of the perforation was the rupture of the cortical bone to the bone marrow (Figure 1C). The suture was performed with 4-0 nylon surgical monofilament. All procedures were performed by a single operator (IM).

\section{Sample collection}

The animals were submitted to euthanasia after 7 days of surgery, by intraperitoneal overdose of thiopental ( $150 \mathrm{mg} / \mathrm{kg})$. A longitudinal incision was performed following the existing cutaneous scar, the tissues were divulsed and the tibias were removed by disarticulation (Figure 1D). The metaphysis length (from the crest of the tibia to the proximal extremity of the epiphysis) and the distance from the center of the defect to the proximal extremity of the epiphysis of each specimen were measured using a pachymeter (Mitutoyo, Kawasaki, Japan) at a precision of $0.01 \mathrm{~mm}$. Then each tibia was covered with moist gauze containing sterile saline solution of $0.9 \%$ sodium chloride, stored in plastic tubes and frozen at $-20^{\circ} \mathrm{C}$ until the time of analysis.

\section{Three-point bending biomechanical test}

Each sample was submitted to a three-point bending test to failure using a universal testing machine (EMIC DL 2000, Equipamentos e Sistemas de Ensaio Ltda, São José dos Pinhais, Brazil). To avoid bias during the allocation of the experimental groups, the specimens were systematically coded by a blinded
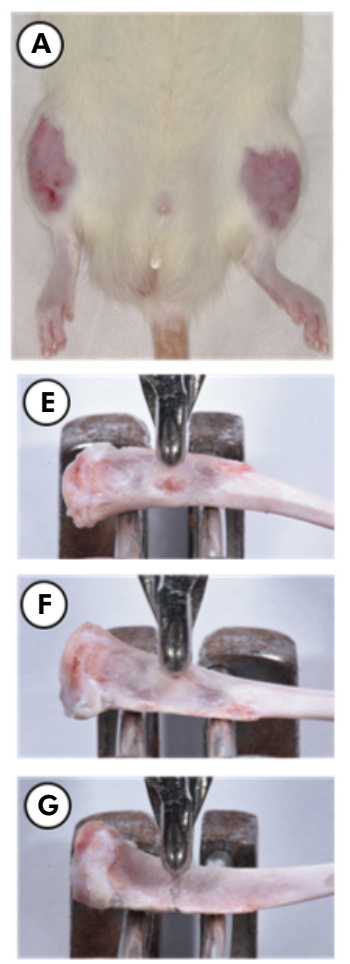
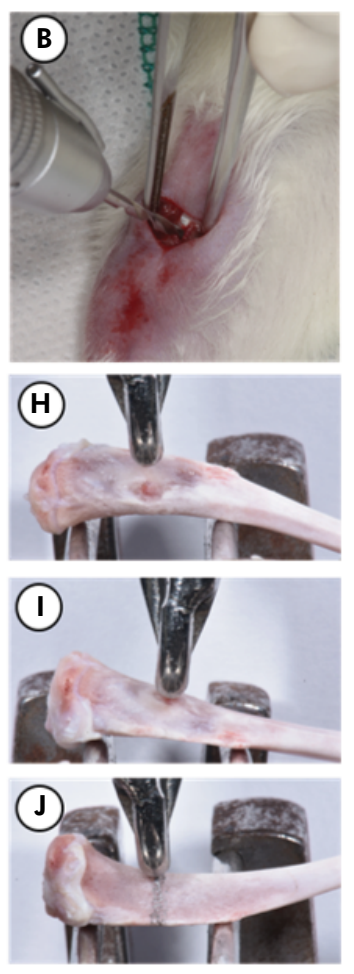
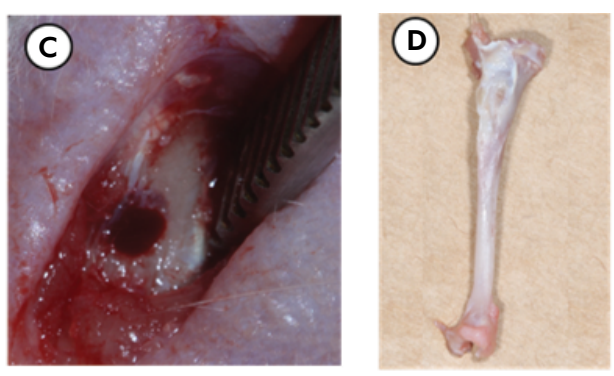

(K)

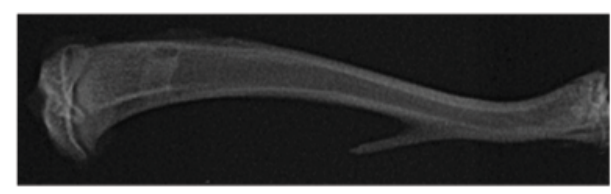

(L)

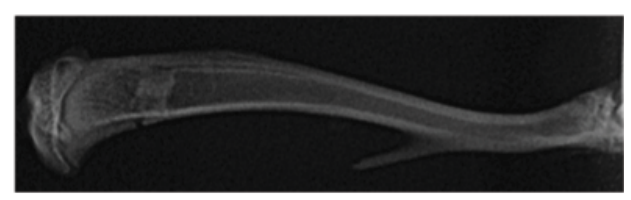

Figure 1. Surgical procedure and positioning of the tibia during three-point bending test on the rat tibia. Radiographics shows the tibia before and after the test. A. Trichotomy on the tibia; B. Creation of the bone defect in standardized location on the tibia methaphisis; C. Bone defect of $1.6 \mathrm{~mm}$ diameter; D. Removal of the tibia by disarticulation; Positioning of the load pplication in relation to the bone defect: E. frontal; F. upward; G. and downward with $6 \mathrm{~mm}$ of distance between the supports; $H$. frontal; I. upward; J. and downward with $10 \mathrm{~mm}$ of distance between the supports; K. Radiographic image of the tibia before three-point bending test; L. Radiographic image of the tibia after three-point bending test showing crack propagation in the bone defect area. 
third person and randomly distributed into six groups $(n=10)$ generated by combinations of the two study factors: bone defect position during load application and span configurations $(6.0$ and $10 \mathrm{~mm}$ between supports).

The bone specimens were positioned horizontally on two supports. The distance between the two lower supports (span) was 6.0 or $10.0 \mathrm{~mm}$. A metallic rod centered between the supports and attached to a 50 $\mathrm{kgf}$ load cell applied was lowered at $1.0 \mathrm{~mm} / \mathrm{min}$ to load the metaphysis. The center of the metaphysis, which was the location of the bone repair area (bone defect), was positioned upward, frontal (toward the operator) or downward (Figure 1E-J). The loading device and the two supports had rounded surfaces ( $2.0 \mathrm{~mm}$ diameter). The load and displacement of the loading device were recorded during each experiment until fracture. The maximum load at failure values $(\mathrm{N})$ were collected from the load data and the stiffness $(\mathrm{N} / \mathrm{mm})$ was calculated as the slope of the initial linear uploading portion of the curves.

\section{Radiographic analysis}

Digital radiography images were obtained before and after the three-point bending test (Gnatus, Barretos, Brazil) at $70 \mathrm{kV}, 7 \mathrm{~mA}$, and 0.12 seconds in combination with VistaScan phosphor plates $3 \times 4 \mathrm{~cm}$ (Dürr Dental, Bietigheim-Bissingen, Germany). Phosphor plates were scanned by using a VistaScan Mini View. The were analyzed using DBSWIN 5.2.0 software supplied with the VistaScan system, to evaluate the fracture pattern (Figure 1K-L).

\section{D finite element model generation}

Five representative specimens were scanned by a high-resolution micro-CT SkyScan 1272 (Bruker, Kontich, Belgium) (Figure 2A-B). The images had approximately 880 slices with image pixel size of $16.31 \mu \mathrm{m}$, obtained with exposure parameters of $80 \mathrm{kV}$ and $125 \mu \mathrm{A}$, using filter aluminum of $1 \mathrm{~mm}$. The micro-CT projection data were exported in Device Independent Bitmap (BMP) format and imported into an interactive medical imaging software (Mimics 21.0, Materialise NV, Leuven, Belgium). The segmentation of the different structures (compact bone, cancellous marrow and bone defect) was accomplished using image density thresholding (Figure 2C-D). After segmentation, the 3D triangle-based surfaces of each bone structure (Figure 2E) were exported in stereo lithography (STL) format. The STL surface models were imported and meshed in MSC.Patran ${ }^{\circledR} 2010$ (MSC software, Santa Ana, USA) and optimized with 3-Matic 8.0 (Materialize NV, Belgium) (Figure 2 F-G). The created volumetric element mesh was imported in a finite element analysis software package (MSC. Marc/Mentat, MSC software, USA) to perform the analysis. All materials were considered linear-elastic, isotropic, and homogeneous. ${ }^{17}$ The elastic modulus and Poisson's ratio of the different structures were obtained from the literature (Table 1). ${ }^{18,19,20}$

To simulate the three-point bending test, three triangular surfaces with rounded corners, similar to the experimental conditions were constructed. All bone models $(n=5)$ were analysed in three different bone defect orientations (upward, frontal and downward) and for two distances between the lower supports $(6$ and $10 \mathrm{~mm}$ ) (Figure 2H-M), resulting in 30 analyses. The interfaces between the different tibia tissues were considered bonded, while the frictional contact coefficient between bone and metallic supports was 0.5. The two lower supports were rigidly fixed while the upper device was free in vertical direction for delivering the load. The boundary conditions were imposed according to the experiments, the tibia was allowed to adapt to the supports during the application of the load. The three-point bending test loading was simulated by applying a $50 \mathrm{~N}$ load in 11 increments. The von Mises equivalent stress and load-displacement ratio were recorded for all finite element models.

\section{Statistical analysis}

The maximum force $(\mathrm{N})$ and stiffness $(\mathrm{N} / \mathrm{mm})$ data were tested for normal distribution (ShapiroWilk's test) and equality of variances (Levene's test), followed by parametric statistical tests. Two-way analysis of variance (ANOVA) was performed to analyze the effect of the position of the defect (3 levels - downward, frontal and upward) and span (2 levels - $6.0 \mathrm{~mm}$ and $10.0 \mathrm{~mm}$ ). Multiple comparisons were made using Tukey's test. All tests were performed using a significance level of $\alpha=0.05$, and all analyses 

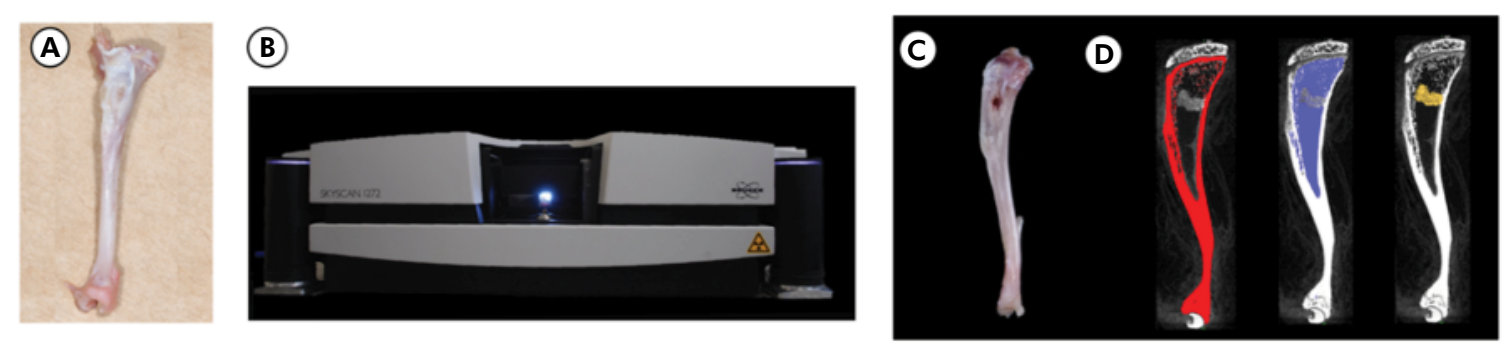

(E)

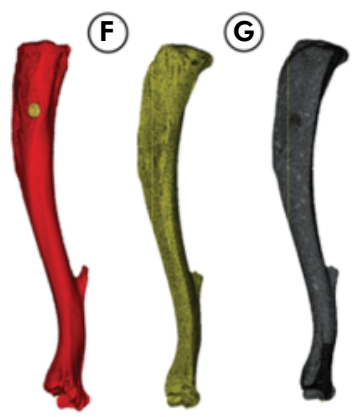

(H)

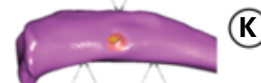

(1)

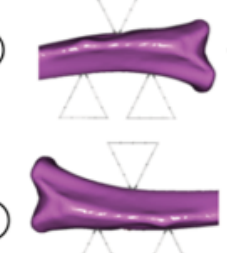

(K)

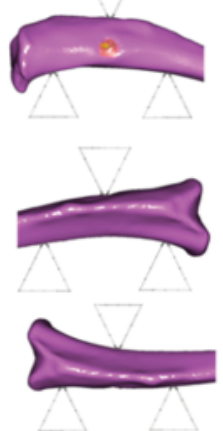

(N)

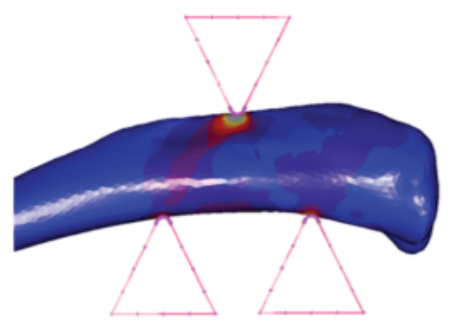

Figure 2. Sequence of 3D models creation for simulation of the three-point bending test on the rat tibia for finite elelement analysis, positioning the bone defect downward, frontal or upward in relation to the load application. A. Representative tibia specimen with bone defect; B. High-resolution Micro-CT; C. BMP file format for bone specimen with defect on metaphysis; D. Segmentation of the cortical, cancellous marrow and bone defecttissues; E. 3D model generated by the Mimics software; F. STL format file before optimization of the mesh; G. Mesh optimization using Patran and 3-Matic softwares; Positioning of the load application in relation to the bone defect: H. frontal; I. upward; J. and downward with $6 \mathrm{~mm}$ of distance between the supports; K. frontal; L. upward; M. and downward with $10 \mathrm{~mm}$ of distance between the supports; $\mathrm{N}$. Finite element analysis post-processing image of the three-point bending test test with $50 \mathrm{~N}$ loading.

Table 1. Mechanical properties used in the FE model.

\begin{tabular}{lccc}
\hline Structure & Elastic modulus (MPa) & Poisson's ratio & References \\
\hline Cortical bone & 20 & 0.3 & 18 \\
Cancellous marrow & 50 & 0.3 & 19 \\
Bone defect & 2100 & 0.3 & 18,20 \\
\hline
\end{tabular}

were performed using the Sigma Plot version 13.1 statistical package (Systat Software Inc., San Jose, USA). The metaphysis lengths, the distances from the defect to proximal epiphysis and the stress distributions from the finite element method were analyzed descriptively.

\section{Results}

The measurement of metaphysis of Wistar rat tibiae analyzed had a length of the $15.3 \pm 0.7 \mathrm{~mm}$. The distance between the bone defect and the proximal epiphysis were $8.2 \pm 0.9 \mathrm{~mm}$.
The maximum force $(\mathrm{N})$ mean and standard deviation values measured in the three-point bending tests of the rat tibia with the defect positioned downward, frontal and upward are shown on Figure 3A. Two-way ANOVA demonstrated a significant effect for defect position $(p=0.030)$, however no significance was found for span distance $(p=0.173)$ and interaction of defect position and span distance $(p=0.913)$. The three-point bending test performed with the frontal defect position resulted in significantly higher maximum forces than when the bone defect was positioned upward and downward. 
The stiffness $(\mathrm{N} / \mathrm{mm})$ mean and standard deviation values for the rat tibia with the defect positioned downward, frontal and upward are shown in F. Two-way ANOVA demonstrated a significant effect for defect position $(\mathrm{p}<0.001)$, however no significance was found for span distance $(p=0.110)$ and interaction of defect position and span distance $(\mathrm{p}=0.406)$. The three-point bending test performed with the frontal defect position resulted in significantly higher stiffness than when the defect was positioned to upward and downward.

The failure mode distributions for the tested samples are shown on Table 2. When the defect was positioned to down, the failure mode involved more area of the prepared defect for both span distances, with the $10.0 \mathrm{~mm}$ span distance resulting in a more evident fracture line. When the defect was positioned frontal, most of the failure modes did not involve the defect region. When the defect was positioned to upward, most of the failure modes involved crushing of the defect region and separation of the epiphysis.

The von Mises stress distributions were visualized to observe general stress patterns. The von Mises stress distributions in the rat tibia when the defect was positioned to downward, frontal and upward for the 6.0 and $10.0 \mathrm{~mm}$ spans for one representative model of the finite element analysis are summarized in the Figure 4 . The use of $10.0 \mathrm{~mm}$ of span distance resulted in a higher stress concentration in the

\section{A}

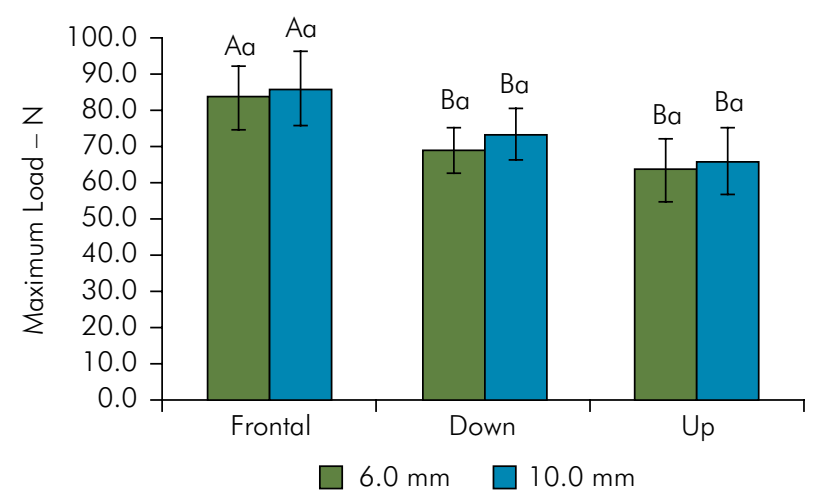

bone area located between load point and inferior supports, mainly in the region opposite of the load application, than for the $6.0 \mathrm{~mm}$ of span distance, irrespective of the defect position. When the defect was positioned to downward, the stress concentrated at the inferior surface close to the bone defect limit and at frontal surface (Figure 4A). When the defect was positioned to frontal, the stress concentrated at the cortical integra of the tibia positioned at inferior surface and at the center of the posterior surface (Figure 4B). When the defect was positioned upward, the stress concentrated at the inferior surface, crest of the tibia and at the center of the posterior surface (Figure 4C).

The von Mises stress distributions in the defect area for the 5 bone tibia models simulating all defect positions and span distances are summarized in Figure 5. When the defect was positioned to downward demonstrated better homogeneity of the stress distribution than when the defects were positioned to frontal or upward (Figure 5A-C). The stresses were more concentrated at the target area (defect area) when the defect was positioned downward (Figure 5A). When the defect was frontally positioned, no stress was observed in the target area (Figure 5B). High stress concentrations were located in a small area of the load application for the models where the defects were positioned upward (Figure 5C). The stress distribution demonstrated good correlation with the failure mode distributions for all experimental

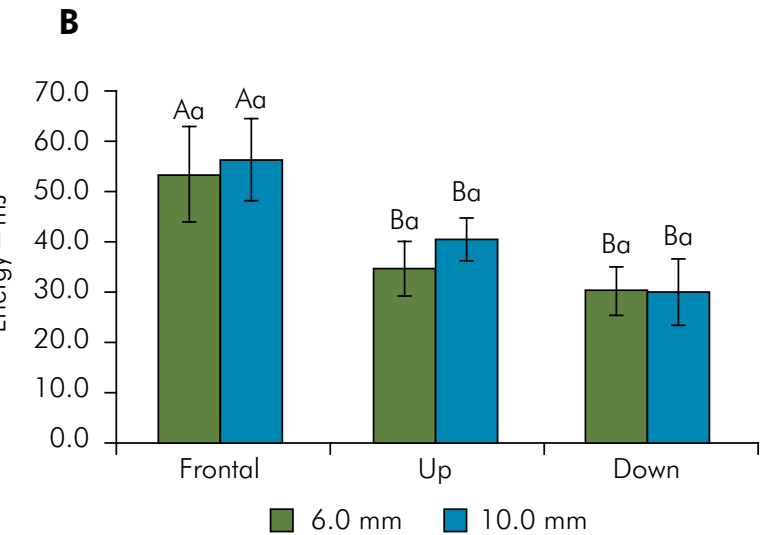

Figure 3. A. Maximum force (N), B. Stiffness $(\mathrm{N} / \mathrm{mm})$ determined experimentally by three-point bending test with the rat tibia $(n=10)$ with the defect positioned downward, frontal or upward and span distances of 6.0 and $10.0 \mathrm{~mm}$. 
Table 2. Classification of the fracture mode for tibiae after three-point bending tests.

\begin{tabular}{|c|c|c|c|c|c|c|c|c|}
\hline \multicolumn{9}{|c|}{ Position of the bone defect } \\
\hline \multicolumn{3}{|c|}{ Downward } & \multicolumn{3}{|c|}{ Frontal } & \multicolumn{3}{|c|}{ Upward } \\
\hline \multicolumn{2}{|c|}{ Span distance } & \multirow[b]{2}{*}{ Fracture modes } & \multicolumn{2}{|c|}{ Span distance } & \multirow[b]{2}{*}{ Fracture modes } & \multicolumn{2}{|c|}{ Span distance } & \multirow[b]{2}{*}{ Fracture modes } \\
\hline $\begin{array}{l}6.0 \mathrm{~mm} \\
(\mathrm{n}=10)\end{array}$ & $\begin{array}{l}10.0 \mathrm{~mm} \\
(\mathrm{n}=10)\end{array}$ & & $\begin{array}{l}6.0 \mathrm{~mm} \\
(\mathrm{n}=10)\end{array}$ & $\begin{array}{l}10.0 \mathrm{~mm} \\
(\mathrm{n}=10)\end{array}$ & & $\begin{array}{l}6.0 \mathrm{~mm} \\
(\mathrm{n}=10)\end{array}$ & $\begin{array}{l}10.0 \mathrm{~mm} \\
(\mathrm{n}=10)\end{array}$ & \\
\hline 4 & 3 & $\begin{array}{l}\text { Starting at defect } \\
\text { surface involving } \\
\text { frontal surface } \\
\text { reaching to superior } \\
\text { loading point }\end{array}$ & 6 & 3 & $\begin{array}{l}\text { Staring at loading } \\
\text { point involving } \\
\text { posterior surface } \\
\text { reaching the inferior } \\
\text { surface at the } \\
\text { center of span - no } \\
\text { involvement of defect }\end{array}$ & 5 & 5 & $\begin{array}{l}\text { Crushing the defect } \\
\text { area with fracture line } \\
\text { at superior involving } \\
\text { the initial of the } \\
\text { anterior and posterior } \\
\text { surfaces. }\end{array}$ \\
\hline 1 & 4 & $\begin{array}{l}\text { Starting at defect } \\
\text { surface involving all } \\
\text { surfaces dividing the } \\
\text { sample at defect line }\end{array}$ & 2 & 4 & $\begin{array}{l}\text { Staring at loading } \\
\text { point involving } \\
\text { posterior surface } \\
\text { reaching in diagonal } \\
\text { line the condyle - no } \\
\text { involvement of defect }\end{array}$ & 1 & 0 & $\begin{array}{l}\text { Crushing the defect } \\
\text { area with fracture line } \\
\text { involving posterior } \\
\text { surface. }\end{array}$ \\
\hline 4 & 2 & $\begin{array}{l}\text { Starting at defect } \\
\text { involving inferior } \\
\text { surface only }\end{array}$ & 2 & 3 & $\begin{array}{l}\text { Staring at loading } \\
\text { point involving } \\
\text { posterior and inferior } \\
\text { surfaces at the center } \\
\text { of span reaching the } \\
\text { base of defect }\end{array}$ & 1 & 3 & $\begin{array}{l}\text { Crushing the defect } \\
\text { with total fracture of } \\
\text { the sample in diagonal } \\
\text { line to the inferior } \\
\text { support close to the } \\
\text { condyle }\end{array}$ \\
\hline 1 & 1 & $\begin{array}{l}\text { starting at load area } \\
\text { involving frontal } \\
\text { surface reaching } \\
\text { condyle at inferior } \\
\text { support area }\end{array}$ & & & & 3 & 2 & $\begin{array}{l}\text { Crushing he defect } \\
\text { area, with no evident } \\
\text { fracture in this area. } \\
\text { Fracture starting at } \\
\text { inferior support area } \\
\text { involving posterior } \\
\text { surface. }\end{array}$ \\
\hline
\end{tabular}

conditions. The Maximum Principal Stresses (tensile stress) on the bottom of the bone, between the two spans of the bending test for the 5 bone tibia models simulating all defect positions and span distances are summarized in Figure 6. When the defect was positioned to downward demonstrated that the tensile stress fit better the bone defect that is the target location to be tested (Figure 6A).

The mean values of the relation between force $(\mathrm{N})$ and displacement $(\mathrm{mm})$ obtained from 0 to $50 \mathrm{~N}$ in the experiments and by the finite element analysis are shown on Figure 7A and 7B, respectively. The curves showed similar behavior, however the values calculated experimentally were always higher than finite element analysis values. When the defect was positioned to frontal, the displacement values were lower, followed by defect positioned downward, and upward.

\section{Discussion}

Several studies have used long bones from animal models to evaluate the bone repair process and therapeutic approaches. ${ }^{5,21}$ Three-point bending tests are one of the main biomechanical tests used to determine bone fracture resistance. Ensuring comparable and repeatable results, however, requires standardization..$^{22}$ The results of the present study demonstrated that positioning of the bone on the supports and the distance between the supports during the load application had a significant influence on the fracture pattern, stress distribution and force $v s$ displacement relation. Additionally, the span distance also influenced the maximum force and stiffness. Therefore, the null hypothesis was rejected.

Bone exhibits a varied arrangement of material structures at different scales, each playing a role in 


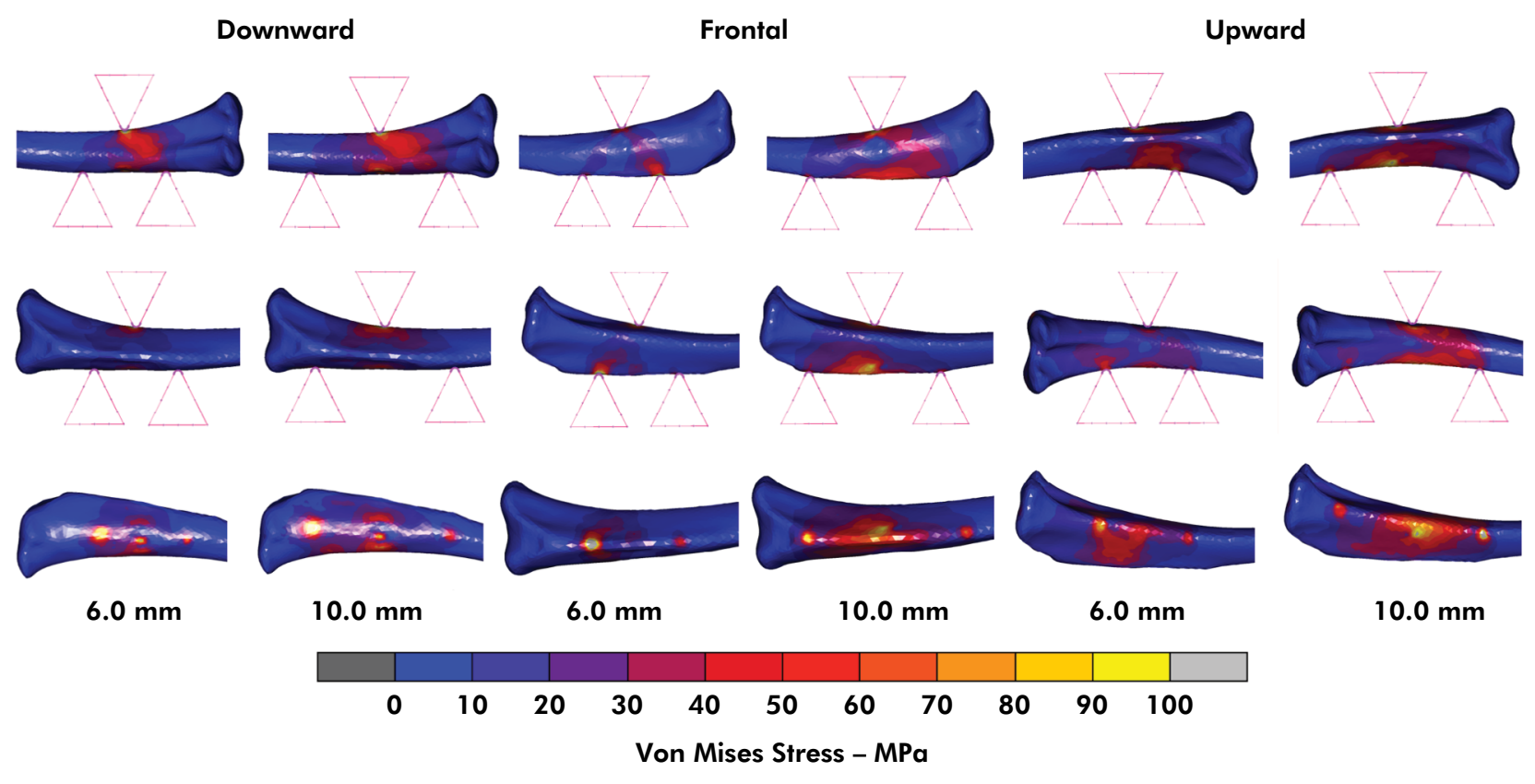

Figure 4. Von Mises stress distributions at frontal, posterior and inferior surfaces of rat tibiae during three-point bending test simulation when the defect was positioned downward, frontal or upward.

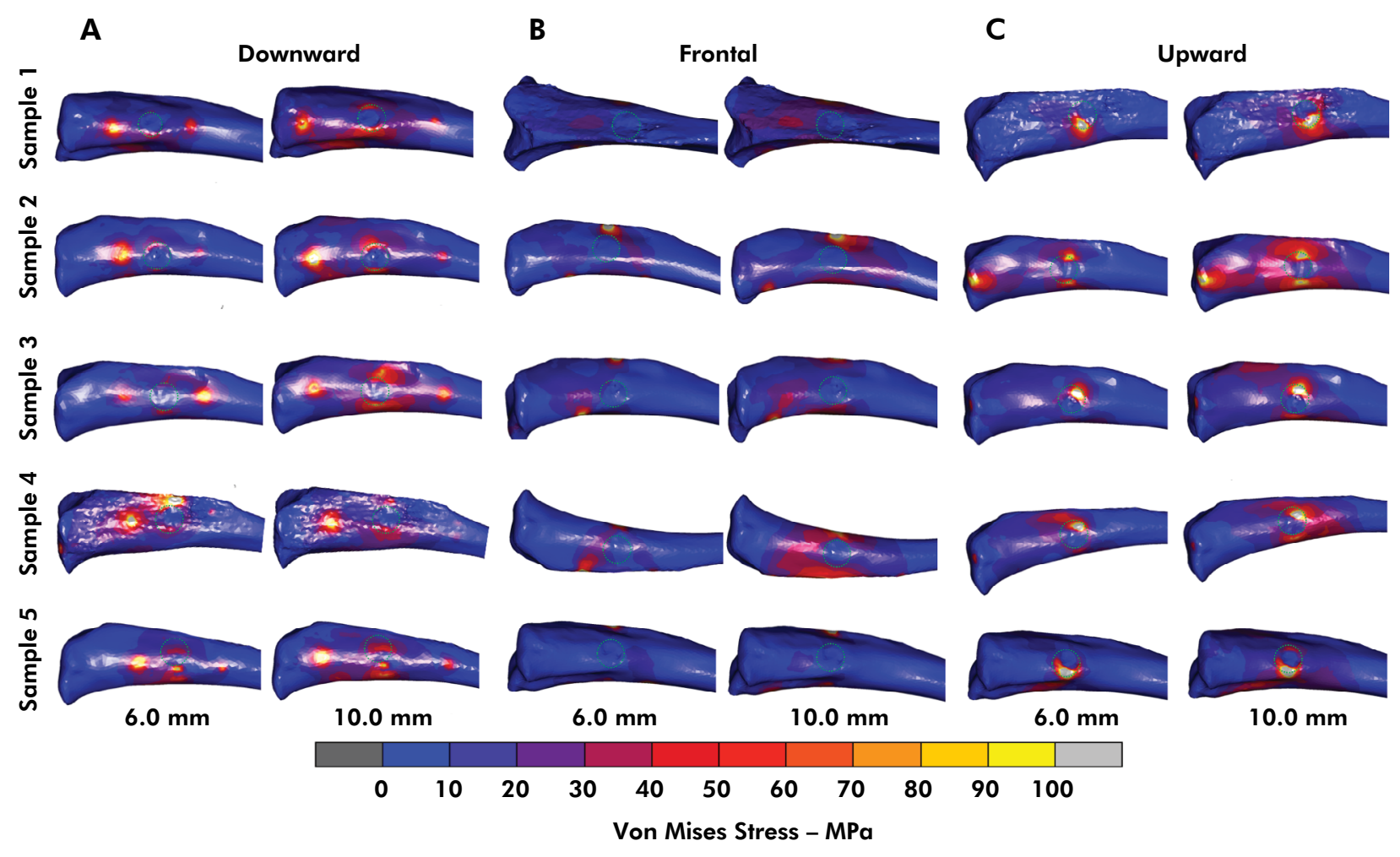

Figure 5. Von Mises stress distributions at the surface of the rat tibiae when the defect was positioned downward, frontal or upward during three-point bending testing. 


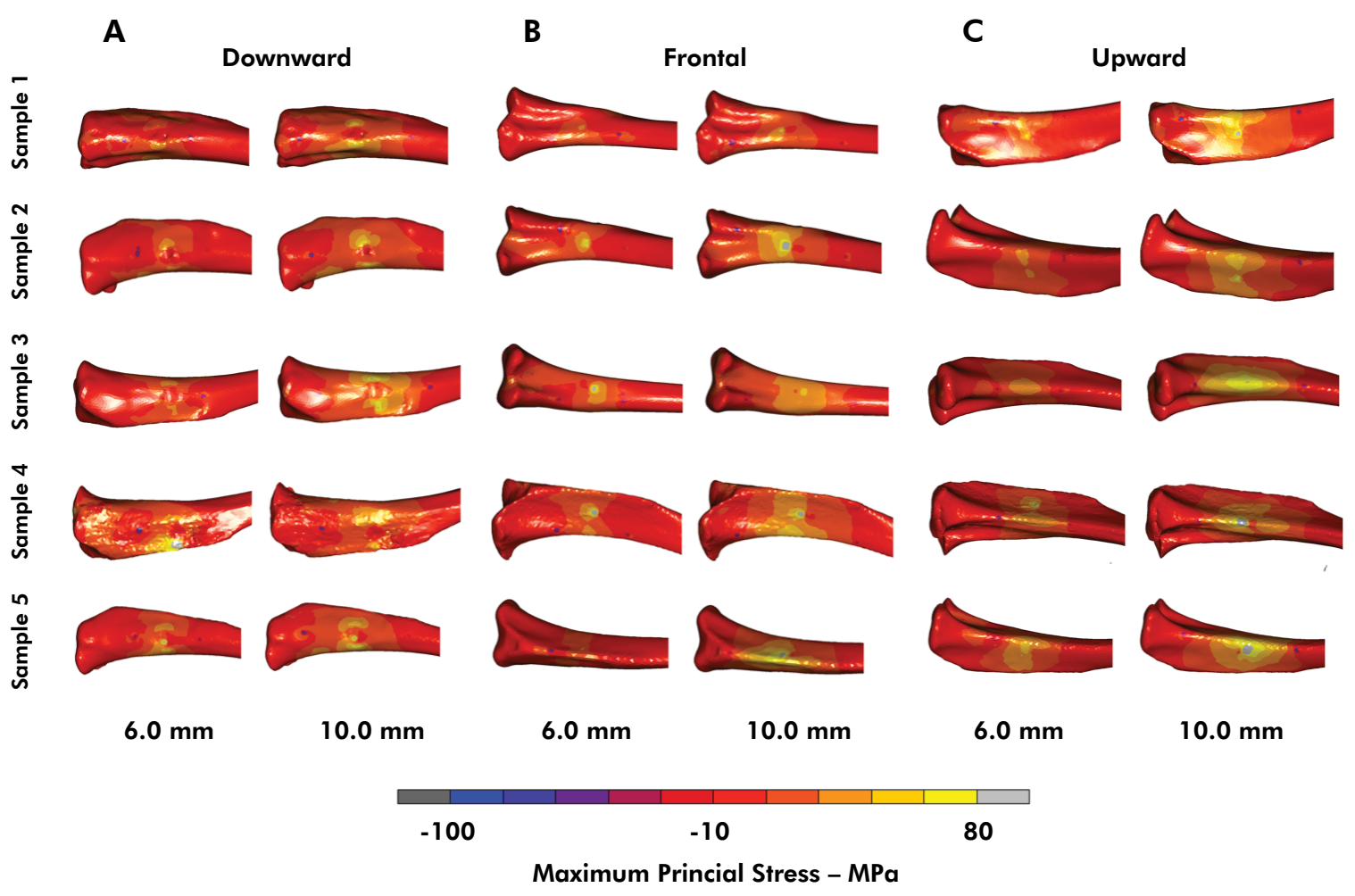

Figure 6. Maximum Principal Stresses (tensile stress) on the bottom of the bone, between the two spans of the bending test.

A

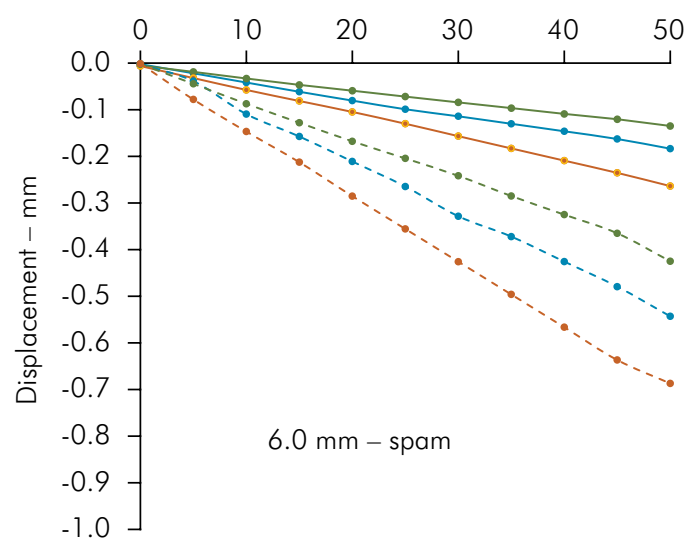

B
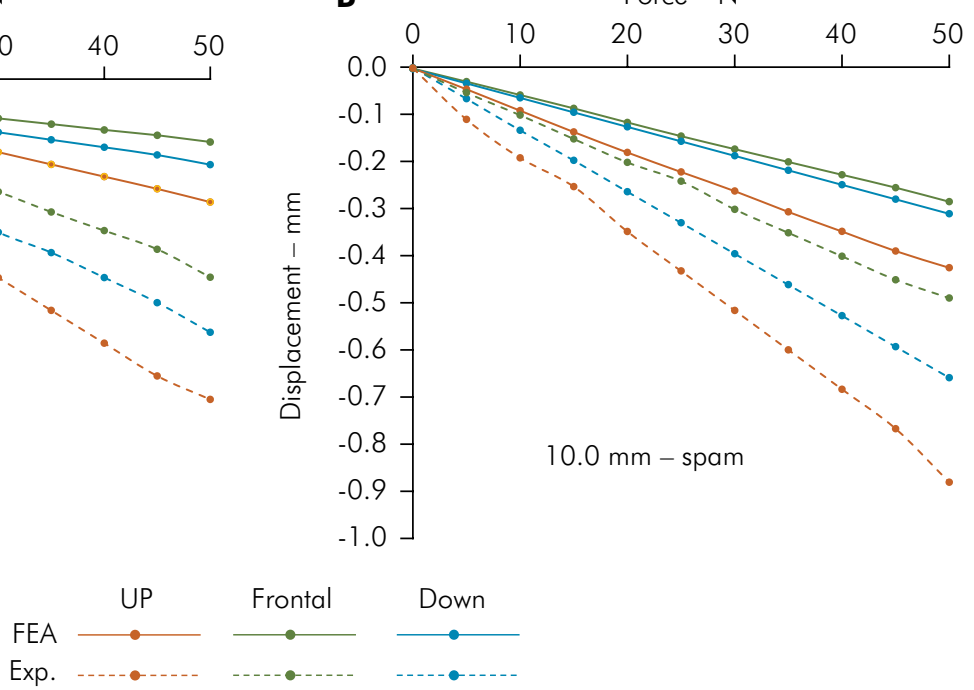

Frontal Down

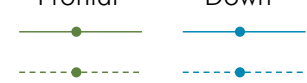

Figure 7. Force $(\mathrm{N})$ versus displacement $(\mathrm{mm})$ relations obtained from finite element analysis (FEA) or experiments during the three-point bending tests with rat tibia for 2 span distances and three bone defect positions (frontal, upward and downward).

its mechanical, biological and chemical functions. Different test methodologies may test different resolutions. Therefore, a combination of techniques may be required to assess bone behavior. ${ }^{23} \mathrm{We}$ evaluated bone repair using a three-point bending test and rat tibia. Long bones, such as tibiae and 
femurs, are widely used to investigate bone repair characteristics. We studied the metaphysis region because this area plays an important role in bone biology research of cortical defect healing, particularly for alterations in trabecular bone architecture. ${ }^{24,25,26}$ Although the three-point bending test is a common method to measure fracture resistance in the metaphysis region, ${ }^{27}$ there is still a lack of standardization. The three-point bending test can provide the flexural strength, elastic modulus and other mechanical characteristics (beam flexure). Standardized geometric specimens are usually used for three-point bending test, then the crosssection area and dimensions are well defined, and a mathematical formula can be easily applied to calculate the flexural strength (MPa). For experiments that use long bone specimen, like was used in the present study, the cross-section area and dimensions are difficult to measure and to standardize. The use of stiffness $(\mathrm{N} / \mathrm{mm})$ and maximum load $(\mathrm{N})$ are more recommended to demonstrate the three-point bending outcome.

The length of the metaphysis and the proximity to the articular surface imposes limitations on potential three-point bending configurations. We evaluated the effect of the bone defect position and the span distance. Using finite element analysis, we observed that the stress concentration is higher in the target area (bone defect) in the group with downward facing defects (Figure 6). The experiments confirmed that the fracture pattern ran through the bone defect in this group. These observations can be explained by the fact that bending deformation causes tensile stresses on the convex side (lower surface) and compressive stresses on the concave side (upper surface). As bone is less resistant to tensile stress, the fracture is most likely to be initiated at the surface under tensile stress. ${ }^{11}$ The downward facing defect was also located in the area (middle between lower supports) where the tensile stresses were the highest. By comparing the von Mises equivalent stress distributions, we observed greater data homogeneity in the experimental group with downward facing defects when compared to the other groups, regardless of the distance of the supports, which supports the notion that the outcomes from this configuration represent the influence of the bone defect most clearly. When the bone defect was facing upward, the defect was located in the compression area where the defect was less likely to initiate fracture. Coinciding the upward facing defect with the area of load application location is an unfavorable design that is unlikely to yield predictable or useful outcomes and should be avoided. With the defect in the frontal position, the defect was located in the lowest stressed surface area. We observed higher failure loads in the latter configuration, which may be explained by the defect being moved out of the higher stressed areas and thus less likely to weaken the tibia. Differences in load-displacement curves (Figure 7) cannot be attributed to the location of defects because they represent tibia stiffness (load/displacement) in particular bending directions, which are mostly differentiated by anatomical shape rather than small local defects. Increasing the span reduced stiffness (reduced load/displacement slope) as expected because bending displacement will increase under the same load.

Besides the defect location, span distance is an important parameter in standardizing three-point bending tests because it changes the structural tibia responses and thus outcomes. Variation in span leads to non-comparable fracture load and stiffness data. Some authors haveused $15-25 \mathrm{~mm}$ span distance to evaluate bone repair in the metaphysis, but often the target area is too short. ${ }^{1718,19}$ Lesion positions were not specified in the aforementioned studies. Our study required shorter spans and showed higher maximum load values in models with $6 \mathrm{~mm}$ span distance compared to $10 \mathrm{~mm}$. However, the longer $10 \mathrm{~mm}$ span generated more consistent flexural stress conditions that concentrated mainly in the opposite side to the load application and resulting in failures modes with more evident fracture lines. Maximizing span distance has been recommended for more consistent and reliable results. ${ }^{28}$

The 3D finite elements models of three-point bending test created from 5 tibias provided further data to analyze the stress distribution during the experiment without methodological bias while considering some anatomical variations. The stress distributions, especially in the internal structure of the bone, cannot be obtained from experimental tests. ${ }^{11}$ The 
finite element analysis also allowed testing different defect locations and spans using the same model because it is a non-destructive method. Furthermore, finite element analysis can minimize the number of animals needed in the experiment, which conforms to the guidelines for ethical conduct in the care and use of animals. ${ }^{29}$ Comparison of the force-displacement response between the finite element and experimental methods showed consistency of the results, thus validating the modeling of the general behavior. The validated FEA models provided an explaination for the experimental fracture patterns. Greater concentration of tensile stresses was shown where the fracture initiated, supporting the recommendation to have the bone defects face downward during the bending test.

Among the limitations of the present study is the assumption of linear, isotropic and homogeneous materials in the finite element analysis. Biomechanical behavior of bone is considered complex due to its viscoelastic, anisotropic and heterogeneous characteristics, attributed to its macro-, micro- and nanostructure. ${ }^{11,23}$ Although these assumptions may have affected the total amount of displacement, the general tibia behavior in the finite element models was validated with the experimental results.

\section{Conclusions}

Therefore, from our results the following recommendations can be made for three-point bending tests on rat tibia:

a. Create the bone defect at $8 \mathrm{~mm}$ from the extremity of the proximal epiphysis to allow a correct downward positioning of the defect, improve stability on the supports in a flat area, and to ensure trabecular bone in the repair area;

b. Use a $10.0 \mathrm{~mm}$ span distance with the downward positioning of the defect, mark the perimeter where the defect is located in order to apply the load in the same direction as the defect;

c. Stabilize the bone in the support before load application, which is easily handled considering the stability provided by the triangular morphology of the tibia.

d. Finally, try to combine biomechanical experiments with finite element analysis for more comprehensive analysis of the tibia performance.

\section{References}

1. Freidouni M, Nejati H, Salimi M, Bayat M, Amini A, Noruzian M, et al. Evaluating glucocorticoid administration on biomechanical properties of rats' tibial diaphysis. Iran Red Crescent Med J. 2015 Mar;17(3):e19389. https://doi.org/10.5812/ircmi.19389

2. Fridoni M, Masteri Farahani R, Nejati H, Salimi M, Gharavi SM, Bayat M, et al. Evaluation of the effects of LLLT on biomechanical properties of tibial diaphysis in two rat models of experimental osteoporosis by a three point bending test. Lasers Med Sci. 2015 Apr;30(3):1117-25. https://doi.org/10.1007/s10103-014-1706-1

3. Prodinger PM, Bürklein D, Foehr P, Kreutzer K, Pilge H, Schmitt A, et al. Improving results in rat fracture models: enhancing the efficacy of biomechanical testing by a modification of the experimental setup. BMC Musculoskelet Disord. 2018 Jul;19(1):243. https://doi.org/10.1186/s12891-018-2155-y

4. Varela A, Chouinard L, Lesage E, Guldberg R, Smith SY, Kostenuik PJ, et al. One year of abaloparatide, a selective peptide activator of the PTH1 receptor, increased bone mass and strength in ovariectomized rats. Bone. 2017 Feb;95:143-50. https://doi.org/10.1016/i.bone.2016.11.027

5. Histing T, Garcia P, Holstein JH, Klein M, Matthys R, Nuetzi R, et al. Small animal bone healing models: standards, tips, and pitfalls results of a consensus meeting. Bone. 2011 Oct;49(4):591-9. https://doi.org/10.1016/i.bone.2011.07.007

6. Komrakova M, Fiebig J, Hoffmann DB, Krischek C, Lehmann W, Stuermer KM, et al. The advantages of bilateral osteotomy over unilateral osteotomy for osteoporotic bone healing. Calcif Tissue Int. 2018 Jul;103(1):80-94. https://doi.org/10.1007/s00223-018-0392-6

7. Stürmer EK, Seidlová-Wuttke D, Sehmisch S, Rack T, Wille J, Frosch KH, et al. Standardized bending and breaking test for the normal and osteoporotic metaphyseal tibias of the rat: effect of estradiol, testosterone, and raloxifene. J Bone Miner Res. 2006 Jan;21(1):89-96. https://doi.org/10.1359/JBMR.050913

8. Stuermer EK, Sehmisch S, Rack T, Wenda E, Seidlova-Wuttke D, Tezval M, et al. Estrogen and raloxifene improve metaphyseal fracture healing in the early phase of osteoporosis. A new fracture-healing model at the tibia in rat. Langenbecks Arch Surg. 2010 Feb;395(2):163-72. https://doi.org/10.1007/s00423-008-0436-x 
9. Tao ZS, Zhou WS, Tu KK, Huang ZL, Zhou Q, Sun T, et al. Effect exerted by teriparatide upon repair function of $\beta$-tricalcium phosphate to ovariectomised rat's femoral metaphysis defect caused by osteoporosis. Injury. 2015 Nov;46(11):2134-41. https://doi.org/10.1016/j.injury.2015.07.042

10. Ishida H, Komaba H, Hamano N, Yamato H, Sawada K, Wada T, et al. Skeletal and mineral metabolic effects of risedronate in a rat model of high-turnover renal osteodystrophy. J Bone Miner Metab. 2020 Jul;38(4):501-10. https://doi.org/10.1007/s00774-020-01095-0

11. Steiner M, Volkheimer D, Meyers N, Wehner T, Wilke HJ, Claes L, et al. Comparison between different methods for biomechanical assessment of ex vivo fracture callus stiffness in small animal bone healing studies. PLoS One. 2015 Mar;10(3):e0119603. https://doi.org/10.1371/journal.pone.0119603

12. Leppänen $\mathrm{OV}$, Sievänen $\mathrm{H}$, Järvinen TL. Biomechanical testing in experimental bone interventions: may the power be with you. J Biomech. 2008;41(8):1623-31. https://doi.org/10.1016/i.jbiomech.2008.03.017

13. Prodinger PM, Foehr P, Bürklein D, Bissinger $\mathrm{O}$, Pilge $\mathrm{H}$, Kreutzer $\mathrm{K}$, et al. Whole bone testing in small animals: systematic characterization of the mechanical properties of different rodent bones available for rat fracture models. Eur J Med Res. 2018 Feb;23(1):8. https://doi.org/10.1186/s40001-018-0307-z

14. Mackert GA, Hirche C, Harhaus H, Kotsougiani D, Hoener B, Kneser U, et al. A novel device for resistance-free biomechanical testing of the metaphysis of long bones. BMC Musculoskelet Disord. 2014 Jul;15(1):245. https://doi.org/10.1186/1471-2474-15-245

15. Brandi ML. Microarchitecture, the key to bone quality. Rheumatology (Oxford). 2009 Oct;48(4 Suppl 4):iv3-8. https://doi.org/10.1093/rheumatology/kep273

16. Boccaccio A, Ballini A, Pappalettere C, Tullo D, Cantore S, Desiate A. Finite element method (FEM), mechanobiology and biomimetic scaffolds in bone tissue engineering. Int J Biol Sci. 2011 Jan;7(1):112-32. https://doi.org/10.7150/ijbs.7.112

17. Zhang G, Xu S, Yang J, Guan F, Cao L, Mao H. Combining specimen-specific finite-element models and optimization in cortical-bone material characterization improves prediction accuracy in three-point bending tests. J Biomech. 2018 Jul;76:103-11. https://doi.org/10.1016/i.jbiomech.2018.05.042

18. Kawarizadeh A, Bourauel C, Zhang D, Götz W, Jäger A. Correlation of stress and strain profiles and the distribution of osteoclastic cells induced by orthodontic loading in rat. Eur J Oral Sci. 2004 Apr;112(2):140-7. https://doi.org/10.1111/i.1600-0722.2004.00116.x

19. de Barros E Lima Bueno R, Dias AP, Ponce KJ, Wazen R, Brunski JB, Nanci A. Bone healing response in cyclically loaded implants: comparing zero, one, and two loading sessions per day. J Mech Behav Biomed Mater. 2018 Sep;85:152-61. https://doi.org/10.1016/i.jmbbm.2018.05.044

20. Cory E, Nazarian A, Entezari V, Vartanians V, Müller R, Snyder BD. Compressive axial mechanical properties of rat bone as functions of bone volume fraction, apparent density and micro-ct based mineral density. J Biomech. 2010 Mar;43(5):953-60. https://doi.org/10.1016/i.jbiomech.2009.10.047

21. Wong RM, Choy MH, Li MC, Leung KS, K-H Chow S, Cheung WH, et al. A systematic review of current osteoporotic metaphyseal fracture animal models. Bone Joint Res. 2018 Jan;7(1):6-11. https://doi.org/10.1302/2046-3758.71.BJR-2016-0334.R2

22. Leppänen $O$, Sievänen $H$, Jokihaara J, Pajamäki I, Järvinen TL. Three-point bending of rat femur in the mediolateral direction: introduction and validation of a novel biomechanical testing protocol. J Bone Miner Res. 2006 Aug;21(8):1231-7. https://doi.org/10.1359/jbmr.060511

23. Rho JY, Kuhn-Spearing L, Zioupos P. Mechanical properties and the hierarchical structure of bone. Med Eng Phys. 1998 Mar;20(2):92-102. https://doi.org/10.1016/S1350-4533(98)00007-1

24. Batista JD, Sargenti-Neto S, Dechichi P, Rocha FS, Pagnoncelli RM. Low-level laser therapy on bone repair: is there any effect outside the irradiated field? Lasers Med Sci. 2015 Jul;30(5):1569-74. https://doi.org/10.1007/s10103-015-1752-3

25. Limirio PH, Rocha Junior HA, Morais RB, Hiraki KR, Balbi AP, Soares PB, et al. Influence of hyperbaric oxygen on biomechanics and structural bone matrix in type 1 diabetes mellitus rats. PLoS One. 2018 Feb;13(2):e0191694. https://doi.org/10.1371/journal.pone.0191694

26. Limirio PH, Rocha FS, Batista JD, Guimarães-Henriques JC, Melo GB, Dechichi P. The effect of local delivery doxycycline and alendronate on bone repair. AAPS PharmSciTech. 2016 Aug;17(4):872-7. https://doi.org/10.1208/s12249-015-0411-0

27. Ritchie RO, Koester KJ, lonova S, Yao W, Lane NE, Ager JW 3rd. Measurement of the toughness of bone: a tutorial with special reference to small animal studies. Bone. $2008 \mathrm{Nov}$;43(5):798-812. https://doi.org/10.1016/i.bone.2008.04.027

28. Schriefer JL, Robling AG, Warden SJ, Fournier AJ, Mason JJ, Turner CH. A comparison of mechanical properties derived from multiple skeletal sites in mice. J Biomech. 2005 Mar;38(3):467-75. https://doi.org/10.1016/i.jbiomech.2004.04.020

29. Reifenrath J, Angrisani N, Lalk M, Besdo S. Replacement, refinement, and reduction: necessity of standardization and computational models for long bone fracture repair in animals. J Biomed Mater Res A. 2014 Aug;102(8):2884-900. https://doi.org/10.1002/ibm.a.34920 